\title{
International Study on Artemia*. XV. Effect of Light Intensity on Hatching Rate of Artemia Cysts from Different Geographical Origin
}

\author{
Paul Vanhaecke, Annie Cooreman and Patrick Sorgeloos**
}

Artemla Reference Center, State University of Ghent, J. Plateaustraat 22, B-9000 Ghent, Belgium

\begin{abstract}
Artemia cysts from 4 geographical strains were incubated under standard hatching conditions at 5 different light intensities. Hatching rates increased with increasing light intensities. The light-intensity threshold at which the maximal hatching rate was attained, varied from strain to strain. Differences in light sensitivity between the Artemia strains studied can, at least partly, be attributed to variation in chorion characteristics. The hypothesis is discussed that light might act as a diapause inhibitor in marine and freshwater branchiopods.
\end{abstract}

In addition to temperature, salinity, $\mathrm{pH}$, and oxygen content of the incubation medium, light conditions influence the hatching efficiency of Artemia cysts (Sorgeloos, 1980). Increased hatching efficiencies in light, as compared to controls incubated in darkness, was first described for Artemia by Sorgeloos (1973). In the meantime this phenomenon has been confirmed for the same as well as for several other strains by Meade (1976), Royan (1976), Person-Le Ruyet and Salaun (1977) and Spektorova and Syomik (1979).

From a recent review on cyst hatching in Artemia (Sorgeloos, 1980), it appears that hatching rate is much more susceptible than hatching efficiency to fluctuations of temperature and salinity. As a consequence one may expect that varying light intensities also affect the hatching rate in Artemia cysts. Furthermore, since important differences have been reported for various

\footnotetext{
- International interdisciplinary study on Artemia strains coordinated by the Artemia Reference Center, State University of Ghent, Belgium

- 'Bevoegdverklaard Navorser' at the Belgian National Science Foundation (N.F.W.O.)
}

cyst-characteristics (Vanhaecke and Sorgeloos, 1980) the light effect may vary from one Artemia strain to another. We have studied the effect of varying light intensities on the hatching rate of Artemia cysts from 4 geographical strains: Buenos Aires (Argentina), Chaplin Lake (Canada), Great Salt Lake (Utah), and San Pablo Bay (California). From the latter strain both untreated and decapsulated cysts (treated according to methods described in Bruggeman et al., 1979, 1980) have been used for experimentation.

Cylindroconical hatching tubes made of glass were placed at different distances from a fluorescent light tube (Philips, $65 \mathrm{~W}$ ) in order to expose the tubes to light intensities of 20,100,500,1000 and 2000 lux, respectively. For each strain 5 replicate tubes were set up each with $250 \mathrm{mg}$ cysts incubated in $100 \mathrm{ml}$ natural seawater $(35 \mathrm{ppt})$ at $25^{\circ} \mathrm{C}$. The cysts were kept in suspension by gentle air-bubbling. The hatching rate was followed by subsampling at intervals of $1 \mathrm{~h}$ : i. e. 5 subsamples of $250 \mu \mathrm{l}$ each were taken with an automatic micropipet and the number of nauplii counted. This sampling procedure was continued until the maximum hatching efficiency (determined prior to experiments, following the method of Sorgeloos et al., 1978, at 1000 lux) was attained, or until no increases in hatching efficiency were noted in 3 consecutive series of samples. The mean values for the 5 subsamples, taken every hour, were expressed as percentage of the maximal hatching efficiency. For each light experiment hatching percentages were used to calculate nonlinear regression lines, employing the method of orthogonal polynominals. Subjecting these regression lines to an analysis of variance revealed the best fit representing the hatching curve. 
The results for the 4 strains studied are graphically represented in Figure 1. As a general trend, hatching rates increase with increasing light intensities until, from a certain intensity onwards, they remain constant. Great variation is noted among the strains studied: (1) Great Salt Lake cysts, revealed minimal differences in hatching rate in different light intensities. (2) Buenos Aires and San Pablo Bay cysts exhibit, increased sensitivities for light; their light-intensity thresholds are situated between 500 and 1000, respectively, 100 and 500 lux. (3) Chaplin Lake cysts appear to be very sensitive to light; not only their hatching rate but also their hatching efficiency varies considerably as a function of experimental light intensities. (4) In San Pablo Bay cysts, chorion removal results in a drop of the light intensity threshold from 100-500 lux in untreated cysts (Fig. 1 C) to 20-100 lux in decapsulated cysts (Fig. 2).

According to Sorgeloos and Persoone (1975) Artemia cysts are susceptible to light triggering as soon as they have reached full hydration under aerobic conditions. Sorgeloos and Persoone also noted that a minimal dose of light energy is needed to trigger onset of metabolism in the encysted embryo. We extrapolate from our present findings that, as illumination intensity is lowered below the critical light intensity threshold for maximal hatching rate, progressively more accumulation time is needed to reach the triggering dose. As a consequence hatching rate is affected.

Light absorption by the cyst chorion has been reported in Triops by Hempel-Zawitkowska (1970) and in Artemia by Iwasaki et al. (1980). Lowering of the light-intensity threshold in decapsulated versus untreated cysts exemplifies this phenomenon. Strain differences could eventually be attributed to differences in chorion characteristics, e.g. in Buenos Aires, San Pablo Bay and Great Salt Lake Artemia a positive correlation was found between chorion thickness (10.4, 7.6 and $4.7 \mu \mathrm{m}$, respectively; Vanhaecke and Sorgeloos, 1980) and light-intensity threshold ranges for maximal hatching rate (500-1000, 100-500 and 0-20 lux, respectively). This correlation, however, cannot be extrapolated to all Artemia strains; Chaplin Lake cysts, for example, have a thin chorion $(5.35 \mu \mathrm{m}$; Vanhaecke and Sorgeloos, 1980) but require 1000 to 2000 lux to assure a maximal hatching rate. Other parameters could interfere with the chorion-thickness criterium: e.g. differences in concentration of the chorion pigment haematine (Gilchrist and Green, 1960)which is known to be responsible for the light-absorption characteristic of the chorion (Hempel-Zawitkowska, 1970) - or variations in the number of those cysts that do not need a light stimulus and can hatch in

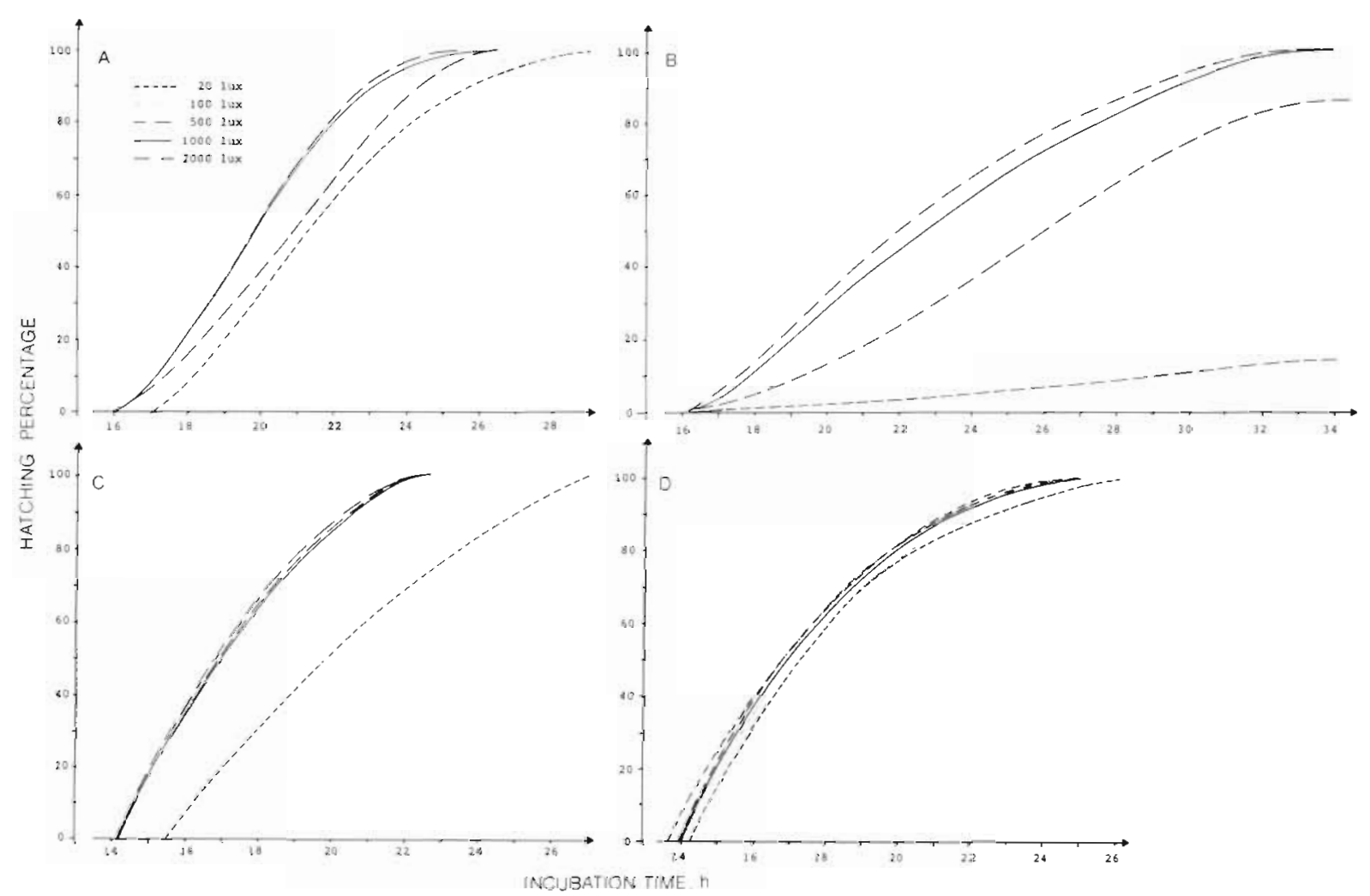

Fig. 1. Artemia sp. Effect of light intensity on hatching rate of cysts from (A) Buenos Aires, (B) Chaplin Lake, (C) San Pablo Bay, (D) Great Salt Lake 


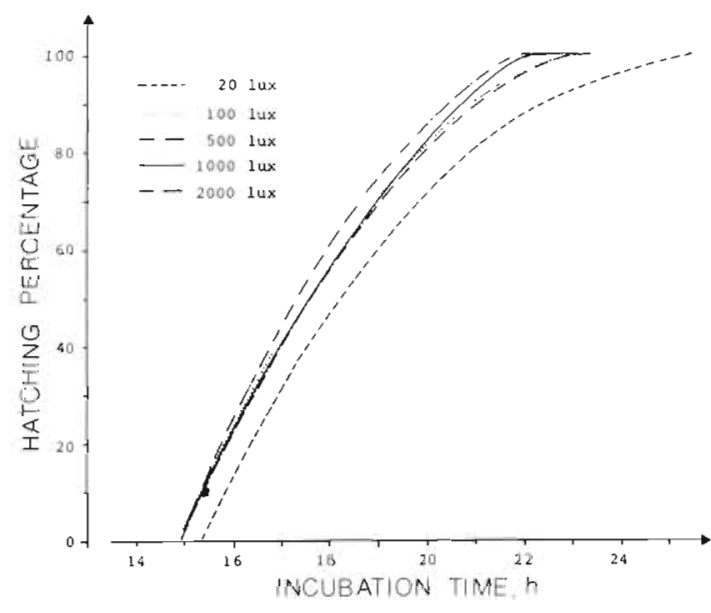

Fig. 2. Artemia sp. Effect of light intensity on hatching rate of decapsulated cysts from San Pablo Bay

darkness (Sorgeloos, 1973), possibly due to differences in cyst-processing and/or cyst-storage conditions (Sorgeloos et al., 1976). In view of important differences between strains reported for many other cyst characteristics (Bruggeman et al., 1980; Vanhaecke and Sorgeloos, 1980), strain-specific differences in the light sensor mechanism can also be expected. As long as this mechanism is not identified, all hypotheses on light triggering of the hatching metabolism in hydrated Artemia cysts must remain speculative.

Since the need for light stimulation in cyst hatching of the freshwater conchostracan Eulimnadia antlei can be removed by drying 'at least in some cases' (Belk, 1972), the light effect on cyst hatching in branchiopods could be a diapauze inhibitor rather than a trigger of hatching metabolism. Indeed various kinds of 'environmental shocks' (Prophet, 1963) have been reported to inhibit diapause and to stimulate nauplii production in branchiopod cysts, e. g. osmotic shock in Branchipus (Mathias and Bouat, 1934); drying in Artemia (Dutrieu, 1960) and in Triops (Klekowski and Hempel-Zawitkowska, 1968); UV-radiation in Triops (Hempel-Zawitkowska, 1970); freezing in Artemia (Hempel-Zawitkowska, 1971a) and in Triops (HempelZawitkowska, 1971b); magnetic fields (Dolgopol'skaya et al., 1969), ionic radiation (Metalli and Ballardin, 1972), exposure to organic solvents (Tazawa and Iwanami, 1974) and cosmic radiation (Planel et al., 1975) all in Artemia. Hatching of a small percentage of brine shrimp cysts in darkness (Sorgeloos, 1973) could then be explained by partial diapause inhibition in the dried cysts.

In conclusion, a better understanding of diapause inhibition in Artemia cysts could eventually lead to improved processing techniques for assuring maximal hatching rates in darkness. In the meantime, minimal light intensities of 1000 lux are advised for hatching
Artemia cysts from origins different from the ones referred to in this paper.

Acknowledgements. This study has been supported by the Belgian National Science Foundation (N.F.W.O.) through Grant F.K.F.O. - 2.0010.78.

\section{LITERATURE CITED}

Belk, D. (1972). The biology and ecology of Eulimnadia antlei Mackin (Conchostraca). SWest. Nat. 16 (3,4): 297-305

Bruggeman, E., Baeza-Mesa, M., Bossuyt, E., Sorgeloos, P. (1979). Improvements in the decapsulation of Artemia cysts. In: Styczynska-Jurewicz, E., Backiel, T., Jaspers, E., Persoone, G. (eds) Cultivation of fish fry and its live food. European Mariculture Society Spec. Publ. No. 4, Institute for Marine Scientific Research, Bredene, pp. 309-315

Bruggeman, E., Sorgeloos, P., Vanhaecke, P. (1980). Improvements in the decapsulation technique of Artemia cysts. In: Persoone, G., Sorgeloos, P., Roels, O., Jaspers, E. (eds) The brine shrimp Artemia, Vol. 3, Ecology, culturing, use in aquaculture. Universa Press, Wetteren, pp. 261-269

Dolgopol'skaya, M. A., Vladimirov, L. V., Taneeva, A. I., Mendeleev, I. S. (1969). Docum. 2nd. All-Union Conf. on the study of the effect of magnetic fields on biological specimens (Russ.). Scientific Council on Complex Problems. Cybernetics Akad. Nauk. SSSR, Moscow, 76 pp.

Dutrieu, J. (1960). Observations biochimiques et physiologiques sur le développement d'Artemia salina Leach. Arch. Zool. exp. gén. 99: 1-134

Gilchrist, B. M., Green, J. (1960). The pigments of Artemia. Proc. R. Soc. (Ser B) 152: 118-136

Hempel-Zawitkowska, J. (1970). The influence of strong ultraviolet radiation on hatchability of Triops cancriformis (Bosc) eggs. Pol. Arch. Hydrobiol. 17 (30): 483-494

Hempel-Zawitkowska, J. (1971a) Resistance of eggs of Artemia salina L. to low temperature. Pol. Arch. Hydrobiol. 18 (3): $287-294$

Hempel-Zawitkowska, J. (1971b). Resistance of eggs of Triops cancriformis (Bosc) to low temperatures as related to several chosen environmental factors. Pol. Arch. Hydrobiol. 18 (3): 295-302

Iwasaki, T., Inada, T., Kawachi, K., Kanai, T., Yamada, T (1980). Usefulness of Artemia in radiobiology: The effects of $60 \mathrm{MeV}$ protons and of synchroton orbital radiation on the eggs. In: Persoone, G., Sorgeloos, P., Roels, O., Jaspers, E. (eds) The brine shrimp Artemia, Vol. 1; Morphology, genetics, radiobiology, toxicology. Universa Press, Wetteren, pp. 181-188

Klekowski, R. Z., Hempel-Zawitkowska, J. (1968). The influence of desiccation at different air humidities on hatchability of Triops cancriformis (Bosc) eggs. Pol. Arch. Hydrobiol. 15: 183-189

Mathias, P., Bouat, M. (1934). Sur le dévelopment de l'oeuf de Branchipus stagnalis. C. r. hebd. Séanc. Acad. Sci., Paris 119: $320-322$

Meade, J. W. (1976). Advances in the intensive rearing of brine shrimp (Artemia salina). Thesis, The Pennsylvania State University, University Park

Metalli, P., Ballardin, E. (1972). Radiobiology of Artemia: Radiation effects and ploidy. Current Topics in Radiation Research Quarterly 7 (2): 181-240

Person-Le Ruyet, J., Salaun, A. (1977). Etude comparative des possibilités d'élevage larvaire de quelques poissons 
marins avec une souche d'oeufs d'Artemia salina de Chypre. ICES C. M./E 32: 1-13

Planel, H., Blanquet, Y., Soleilhavoup, J. P., Kaiser, R., Pianezzi, B. (1975). Effects of cosmic heavy ions on Artemia egg development. In: Radiation research: Biomedical, chemical and physical perspectives. Academic Press, New York, pp. 1152-1163

Prophet, C. W (1963). Some factors influencing the hatching of anostracan eggs. Trans. Kans. Acad. Sci. 66 (1): 150-159

Royan, J. P. (1976). Effect of light on the hatching and growth of Artemia salina. Mahasagar $9(1,2)$ : $83-85$

Sorgeloos, P. (1973). First report on the triggering effect of light on the hatching mechanism of Artemia salina dry cysts. Mar. Biol. 22: 75-76

Sorgeloos, P. (1980). The use of the brine shrimp Artemia in aquaculture. In: Persoone, G., Sorgeloos, P., Roels, O., Jaspers, E. (eds) The brine shrimp Artemia, Vol. 3. Ecology, culturing, use in aquaculture. Universa Press, Wetteren, pp. 25-46

Sorgeloos, P., Baeza-Mesa, M., Benijts, F., Persoone, G. (1976). Current research on the culturing of the brine shrimp Artemia salina L at the State University of Ghent, Belgium. In: Persoone, G., Jaspers, E. (eds) Proc. 10th European Symposium on Marine Biology, Vol. 1, Research in mariculture at laboratory and pilot scale. Universa Press, Wetteren, pp. 473-495

Sorgeloos, P., Persoone, G. (1975). Technological improve- ments for the cultivation of invertebrates as food for fishes and crustaceans. II. Hatching and culturing of the brine shrimp. Artemia salina L. Aquaculture 6: 303-317

Sorgeloos, P., Persoone, G., Baeza-Mesa, M., Bossuyt, E., Bruggeman, E. (1978). The use of Artemia cysts in aquaculture: The concept of 'hatching efficiency' and description of a new method for cyst processing. In: Avault, J. W., Jr. (ed.) Proc. 9th Annual Meeting of the World Mariculture Society, Louisiana State University, Baton Rouge, pp. 715-721

Spektorova, L. V., Syomik, A. M. (1979). The influence of incubation conditions upon Artemia hatching efficiency in three strain models. In: Book of abstracts, International Symposium on the brine shrimp, Artemia salina (Corpus Christi, August 20-23, 1979), Artemia Reference Center, Ghent, p. 127

Tazawa, E., Iwanami, Y. (1974). Hatching of brine shrimp eggs (Artemia salina) soaked in organic solvents. Zool. Mag. Zool. Soc. Jap. 83 (3): 267-269

Vanhaecke, P., Sorgeloos, P. (1980). International Study on Artemia. IV. The biometrics of Artemia strains from different geographical origin. In: Persoone, G., Sorgeloos, P., Roels, O., Jaspers, E. (eds) The brine shrimp Artemia, Vol. 3. Ecology, culturing, use in aquaculture. Universa Press, Wetteren, pp. 393-405

Accepted for printing on January 21, 1981 